\section{Riqueza e rigor científico das abordagens qualitativas}

Giampietro GOBO. Doing ethnography, Thousand Oaks, CA, Sage, 2008. 376 páginas.

\section{Lorenzo Frangi*}

Não se pode produzir conhecimento científico sem que antes se saiba como produzir tal conhecimento. $\mathrm{O}$ desenvolvimento das ciências sociais é marcado por uma disputa interna acerca da metodologia mais adequada para o estudo dos fenômenos sociais e, sobretudo, da validade dos resultados obtidos com a utilização de diferentes métodos e técnicas de pesquisa. Em particular, os defensores das abordagens marcadamente quantitativas têm refutado os métodos qualitativos de pesquisa baseados em argumentos que colocam em suspeita a estrutura e o rigor científico pelo qual o conhecimento é produzido através desses métodos.

Muito embora não seja uma questão nova, trata-se de um debate que não se esgota. Ao contrário, demonstra sua vitalidade e atualidade a cada nova contribuição. Um exemplo é o livro Doing ethnography, do sociólogo italiano Giampietro Gobo, que discorre detalhadamente sobre os aspectos metodológicos que, ao longo de uma história de mais de um século, estruturam a pesquisa etnográfica e se inserem no mais amplo background das abordagens qualitativas. A sistemática e ampla análise contemplada nesse trabalho contribui para a reavaliação das argumentações contrárias às abordagens qualitativas, demonstrando como a etnografia se estruturou a partir de rigor científico próprio, nada inferior a outras abordagens de pesquisa, alimentada por uma reflexividade específica acerca da relação entre teorias e técnicas e entre estas e as práticas de pesquisa.

A análise dessas relações é explorada pelo autor, com base tanto em pesquisas clássicas que marcaram a história da etnografia como por aquelas que representam novas fronteiras de estudos, ressaltando a sólida estrutura que envolve essas pesquisas, o grande aporte que oferecem ao debate metodológico das ciências sociais e o seu potencial desenvolvimento nos contextos contemporâneos.

* Agradeço a Glaucia Marcondes pela revisão do texto em português.
Com um conteúdo estruturado de forma didática, o livro pode ser considerado um instrumento valioso de orientação para estudantes que estão iniciando suas atividades de pesquisa ou docentes interessados na abordagem e no aprofundamento de aspectos metodológicos nas disciplinas que ministram. Duas características centrais fazem dessa obra uma ferramenta útil para esses públicos. Por um lado, reúne de maneira sistemática e bem organizada um material detalhado que explora as potencialidades e os limites do método etnográfico, abordando múltiplos aspectos de exemplos contidos em pesquisas etnográficas de grande reconhecimento no campo das ciências sociais e também de casos retirados de estudos sobre a vida cotidiana. Os exemplos espalham-se ao longo dos capítulos ou em quadros analíticos específicos. Esse vasto material, por sua vez, estimula a reflexividade analítica do leitor, fornecendo elementos que o auxiliam a refletir com maior propriedade sobre a escolha metodológica, as vantagens e os aspectos alinhados à prática etnográfica, assim como das novas fronteiras abertas no debate acadêmico internacional. Outro aspecto que reforça o didatismo do livro é a retomada ao final de cada capítulo dos principais conceitos trabalhados, com indicação de leituras adicionais sugeridas conforme a característica do leitor - não graduado, graduado ou pesquisador especialista - além de testes de autoavaliação sobre a compreensão do conteúdo abordado.

O livro é composto por quatro partes. A primeira situa a etnografia no panorama dos métodos de pesquisa das ciências sociais e discorre sobre os principais momentos de desenvolvimento histórico e da sua consolidação como um "saber fazer" específico de pesquisa. Além da apresentação das grandes escolas que marcaram o nascer dos estudos etnográficos (como a escola de Chicago, o interacionismo, a grounded theory), também abarca os desenvolvimentos mais recentes ("etnografia da recepção" nos estudos das mídias, "etnografia feminista" e "etnografia pós-moderna”) e as novas fronteiras do campo ("etnografia global" e "etnografia institucional”). A primeira parte finaliza destacando a importância do desenho de pesquisa, na atenção adequada e cuidadosa à conceituação do fenômeno a ser estudado, à forma de operacionalização e 
definição da amostra. $\mathrm{O}$ autor igualmente estimula o pesquisador a refletir sobre a identificação e o enfrentamento dos possíveis vieses de pesquisa. Para tal são analisadas as potencialidade e limitações de diversos tipos de amostras, participação e envolvimento de pesquisadores, contribuindo para a conscientização do pesquisador a respeito da precisão de certas escolhas e práticas de pesquisa.

O pensar por variáveis e hipóteses não é descartado, mas, ao contrário, assumido pelo autor como parte inerente a qualquer pensar e fazer científico; contudo, inserido em uma forma de proceder não padronizada (como o fazem as abordagens quantitativas), mas construída ad hoc em relação ao contexto ao qual o pesquisador se debruça. Nesse sentido, é interessante destacar a ênfase dada ao desenho da pesquisa etnográfica como um processo em espiral, no qual uma subsequência de conceitos, hipóteses e indicadores encontram refinamento e foco ao longo do desenvolvimento da pesquisa.

A segunda parte do livro delineia os aspectos mais comuns da fase empírica do estudo etnográfico. Inicialmente, discute o acesso ao campo e os problemas éticos implicados, para depois analisar aspectos referentes aos procedimentos de observação, "como" e "o que" observar, reservando particular atenção a contextos, discursos e estruturas sociais. Na sequência, descreve as técnicas para descobrir as convenções e os significados compartilhados em um âmbito social específico. Novamente o caráter didático do livro se sobressai nos capítulos dedicados à entrevista etnográfica, em que detalha características e dinâmicas de entrevista, e às técnicas de organização e estruturação do diário de campo, ponderando sobre as possibilidades de trabalhar com elaborações estatísticas etnográficas baseadas em uma proposta de contar em vez de mensurar.

$\mathrm{Na}$ terceira parte, o trabalho detém-se no processo de análise do material empírico, esmiuçando com exemplos o complexo problema de desconstrução, construção e confirmação para "documentar” uma hipótese e formular uma teoria. Importante nessa parte é a discussão sobre a legitimação de um estudo, destacando a imprescindível condição de atenção analítica rumo ao "fazer pesquisa", da rigorosidade metodológica no proceder etnográfico e da conceituação apropriada como bases im- portantes para garantir a consistência das generalizações de tipo qualitativo.

$\mathrm{Na}$ parte final, Audiences, o autor trata da comunicação dos resultados e dos problemas relativos à escrita etnográfica, analisando vários estilos e os estímulos reflexivos fornecidos ao pesquisador pelo processo de escrita. Gobo sublinha como a finalização do trabalho de campo também faz parte de um processo, pois deixar o campo não é tarefa simples. Não se trata de "capturar e escapar". A própria forma de encerramento do campo deve ser problematizada pelo pesquisador. Com uma densidade material menor do que as partes anteriores, o último capítulo discute as novas oportunidades de aplicação da observação etnográfica, dos possíveis desdobramentos metodológicos e dos objetos de pesquisa em uma sociedade que cada vez mais pode ser definida como "sociedade da observação".

O livro tem o mérito de apresentar uma reflexão crítica acurada de uma vasta e reconhecida produção etnográfica, constantemente expondo as conexôes entre teorias e práticas de pesquisa; entre o "conhecer" e o "como conhecer". Ao estruturar toda a discussão na experiência etnográfica, permite ao leitor/pesquisador seguir um eixo norteador claro e consistente, fornecendo instrumentos e sugestôes para o enfrentamento adequado e reflexivo dos diversos contextos e fases de uma pesquisa.

$\mathrm{Na}$ ampla abordagem proposta por Gobo, está ausente um aspecto relativo à condução e comunicação dos resultados de pesquisa etnográfica: trata-se do amplo espaço de significados subjacentes à "coragem" do pesquisador. Refere-se às motivaçôes subjetivas do pesquisador envolvidas no processo de pesquisa.

Como poderíamos ter pesquisas fundamentais acerca da marginalidade social se os etnográfos não tivessem tido a coragem de acessar esse tipo de campo? E como poderíamos dispor de etnografias tão ricas e complexas se os pesquisadores não tivessem tido a coragem de persistir na contínua, e às vezes exaustiva, espiral de revisão das relações entre conceitos, hipóteses e interpretações dos fenômenos? Como, ainda, garantir elementos, além da fundamental rigorosidade metodológica, de legitimação da etnografia como método estruturado, sem uma boa dose de coragem para enfrentar as críticas e desconfianças comumente apontadas 
por pesquisadores quantitativos? Isso talvez mereça uma atenção analítica mais profunda, que ajude a esclarecer quais influências a dimensão da coragem pode ter no "conhecer como" e no "conhecer o que" das etnografias.

A qualidade e a relevância científica no campo das ciências sociais de Doing ethnography têm sido reconhecidas por conta de sua publicação em diversos idiomas. Aguardamos, pois, a oportunidade para uma tradução na língua portuguesa.

\section{LORENZO FRANGI é pós-doutorando na HEC-Montréal, Lecturer na Universidade de Montreal e pesquisador do CRIMT. E-mail: <lorenzo.frangi@hec.ca>.}

\section{Uma etnografia dos ricos em São Paulo}

Jessica SKLAIR. A filantropia paulistana: açōes sociais em uma cidade segregada. São Paulo, Humanitas, 2010. 233páginas.

\section{Catarina Morawska Vianna}

Jessica Sklair abre em A filantropia paulistana uma rara brecha que permite ao leitor espreitar a perspectiva dos ricos de São Paulo sobre a desigualdade na cidade, revelada através da etnografia de três programas de responsabilidade social. $\mathrm{O}$ primeiro é o Friendship and Learning Acquisition (FALA), em que adolescentes da Escola Graduada, um colégio norte-americano no bairro do Morumbi, oferecem aulas de inglês para funcionários e jovens da favela de Paraisópolis. No segundo, Programa Einstein na Comunidade de Paraisópolis (PECP), mulheres entre 40 e 60 anos se voluntariam nos serviços gratuitos oferecidos pelo hospital Albert Einstein aos moradores de Paraisópolis, que incluem o atendimento ambulatorial para crianças de 0 a 6 anos, atividades para gestantes e mães e aulas de computação para adolescentes. $\mathrm{O}$ terceiro, Programa Nova Geração (PNG), busca engajar jovens ricos de 18 a 35 anos no debate sobre a desigualdade social para incitá-los a imaginar possíveis formas de atuação.

Além do capítulo introdutório, que discute brevemente a literatura na área de segregação urbana, e outro com considerações finais, o livro conta com três capítulos centrais dedicados a cada um dos programas. O eixo argumentativo que perpassa a obra se baseia numa estratégia que desloca o enfoque ao que chama Caldeira (2000) "enclaves fortificados". Em vez de se debruçar sobre os efeitos das medidas de autossegregação operadas pelas elites, tais como o isolamento apoiado pelo discurso do medo, o reforço da discriminação social e a desvalorização da esfera pública, Sklair explora as tentativas dos que estão dentro dos muros de olhar por sobre eles. O resultado é uma etnografia que revela como iniciativas de responsabilidade social estimulam os atores a elaborar certas visōes do social que explicam a pobreza e a desigualdade; como a noção de responsabilidade 